\title{
The long-term outcomes of interventions for the management of attention-deficit hyperactivity disorder in children and adolescents: a systematic review of randomized controlled trials
}

\author{
This article was published in the following Dove Press journal: \\ Psychology Research and Behavior Management \\ 16 September 2013 \\ Number of times this article has been viewed
}

Jack Parker'

Gill Wales ${ }^{2}$

Nevyne Chalhoub'

Val Harpin ${ }^{2}$

'Child and Adolescent Mental Health Service, Sheffield Children's NHS Foundation Trust, Sheffield, UK;

${ }^{2}$ Paediatric Neurodisability, Ryegate Children's Centre, Sheffield Children's NHS Foundation Trust, Sheffield, UK
Correspondence: Jack Parker CAMHS, Centenary House, 55 Albert Terrace Road, Sheffield, S6 3BR, UK

Tel +44 II 42262310

Fax +44 II 43053075

Email jack.parker@sch.nhs.uk
Purpose: To systematically identify and review the currently available evidence on the long-term outcomes of recommended attention-deficit hyperactivity disorder (ADHD) interventions following randomized controlled trials with children and young people.

Method: A systematic search was conducted to identify trials $>1$ year in length using the following databases: CINAHL (January 1982- July 2012), MEDLINE (Ovid and Cambridge Scientific Abstracts [CSA]), Psych info, Science Direct (Elsevier), and Cochrane Library. Hand searches of key journals in the subject, book chapters, and conference proceedings were also carried out. Relevant papers were critically appraised using the Cochrane risk of bias tool.

Results: Eight controlled trials were identified as being relevant, of duration ranging from 1 year to 8 years (at follow up). The total number of participants in the studies was 1,057, of whom $579(54.7 \%)$ were from one cohort and included 26 different outcome measures. Results suggest there is moderate-to-high-level evidence that combined pharmacological and behavioral interventions, and pharmacological interventions alone can be effective in managing the core ADHD symptoms and academic performance at 14 months. However, the effect size may decrease beyond this period.

Conclusion: This review has highlighted the paucity and limitations of the evidence investigating the long-term outcomes of recommended interventions for managing ADHD symptoms. There is little evidence to suggest that the effects observed over the relatively short term are maintained throughout longer periods of impairment. Furthermore, much of the existing evidence examining effectiveness beyond 12 months does not include newer medications currently available or consider significant contextual and cultural differences, such as UK/ European and Asian populations. Longitudinal studies are required to examine the long-term outcomes for children and young people with ADHD managed with currently recommended service interventions. They should also include the whole spectrum of ADHD, with its full range of coexisting conditions, and cultural and contextual diversity.

Keywords: ADHD, pharmacological intervention, multimodal intervention

\section{Background}

Attention deficit hyperactivity disorder (ADHD) is a highly comorbid, ${ }^{1-3}$ chronic neuropsychiatric disorder with a worldwide prevalence of around 5\% of school age children, ${ }^{4}$ of which up to $80 \%$ to $85 \%$ continue to be impaired by ADHD symptoms as adolescents ${ }^{5-8}$ and up to $60 \%$ into adulthood. ${ }^{9}$

ADHD typically presents with symptoms of inattention, impulsivity, and hyperactivity which can have a profound impact on the individual and their family. ${ }^{9-11}$ 
Children and adolescents with ADHD often have poor social skills, learning difficulties, and disruptive behavior which can result in low self-esteem, disrupted relationships, and academic failure. ${ }^{10} \mathrm{Up}$ to $30 \%$ of ADHD children have an associated learning disorder of reading, writing, and/or mathematics ${ }^{1,12}$ and are more likely to use remedial academic services. Longitudinal studies have also found that ADHD is associated with poorer grades in reading and mathematics, which can often result in a greater likelihood of repeating a school year compared with controls. ${ }^{13}$

Adolescents are also thought more likely to have a history of suspension or expulsion ${ }^{14}$ and a shorter time spent in education. ${ }^{15}$ By their young adult years, they are at greater risk of adverse psychiatric outcomes, including, antisocial, addictive, mood, and anxiety disorders. ${ }^{3,16,17}$ They also have higher rates of conduct disorder, antisocial personality disorder, and substance abuse. ${ }^{18,19}$ Indeed, those diagnosed in childhood have continued to show significantly worse educational, occupational, economic, and social outcomes three decades after initial diagnosis compared with age-matched controls. ${ }^{20}$

Currently in the UK, ADHD is most commonly diagnosed between the ages of 6 and 12 years, ${ }^{21}$ which is often a result of the impact the symptoms have on families, social lives, and academic attainment. ${ }^{10}$ The long-term impact that untreated or poorly treated ADHD can have upon all aspects of the person with ADHD, their family, and importantly, their life chances, is profound. Therefore, the long-term monitoring of the effectiveness of service provision and clinical outcomes that cover the whole spectrum of ADHD is paramount. ${ }^{9}$

\section{ADHD management}

There is high level evidence suggesting that pharmacological treatment can have a major beneficial effect on the core symptoms of ADHD (hyperactivity, inattention, and impulsivity) in approximately $80 \%$ of cases compared with placebo controls, in the short term. ${ }^{22}$ However, although pharmacological treatments are relatively safe, these treatments are not without adverse side-effects, such as, suppression of growth, sleep problems, tiredness, loss of appetite, stomach upset, headaches, nausea, and increases in heart rate and blood pressure. ${ }^{12,23-27}$ Nonpharmacological interventions, such as psychoeducational programs, behavioral interventions, and cognitive behavioral therapy are also recommended. ${ }^{28-30}$ Although there is moderate-to-high-level evidence that nonpharmacological interventions can be effective in managing the core ADHD symptoms, conduct disorders, social skills, self-efficacy, and emotional outcomes at 6 months follow up, ${ }^{28}$ little is known regarding the long-term effectiveness.
With increased awareness and more reliable diagnostic criteria, the number treated with medication in the UK has risen from 0.5 per 1,000 to over 3.0 per 1,000 over the last 30 years. ${ }^{22}$ This has resulted in the number of prescriptions in the UK for stimulant medications increasing from 220,000 (1998) to 418,300 (2004). ${ }^{22}$ A UK cohort followed up after 5 years (ages 15-21) found that almost $69 \%$ of adolescents would still meet the criteria for ADHD, were still known to services, and exhibited high levels of antisocial behavior, criminal activity, and substance abuse. ${ }^{31}$ However, despite the persistence of symptoms, the prevalence of prescribing and adherence to medication drops significantly from the age of 15 years. ${ }^{32}$ This suggests that as children with ADHD move into adolescence and adulthood, their ADHD symptoms may not be managed optimally, resulting in negative repercussions on themselves, their family, and society.

ADHD is the most common reason for follow up by the UK Child and Adolescent Mental Health Services $(\mathrm{CAMHS})^{33}$ and can involve long-term monitoring throughout childhood, adolescence, and into adulthood. However, as a result of an often complex assessment and treatment process, inefficient methods of data collection, and difficulties tracking and monitoring long-term treatment, little is known regarding the long-term outcomes of those receiving recommended service intervention(s)..$^{31,33,34}$

A recent review examined outcomes of individuals with ADHD in nine major outcome categories, and the effect of treatment or nontreatment. Studies of greater than 2 years duration published between 1980 and 2010 were included. They did not study core ADHD symptoms. They concluded that ADHD treatment may reduce but does not remove the negative effects of ADHD. ${ }^{35}$

A further review looked at the effect of long-term (greater than 3 years) treatment on academic outcomes. This concluded that treatment of ADHD improved academic achievement scores but that the evidence for improved school grades was less convincing. The researchers discussed the difficulty in monitoring adherence to treatment in long-term studies and the effect this had on interpreting outcomes. ${ }^{36}$

This review will therefore systematically examine the currently available evidence on long-term outcomes of treating children and young people with ADHD, with regards to symptom control and academic attainment.

\section{Methods}

\section{Data sources and search strategy}

A systematic search was conducted using the following databases: CINAHL (January 1982- July 2012), MEDLINE 
(Ovid and Cambridge Scientific Abstracts [CSA]), Psych info, Science Direct (Elsevier), and the Cochrane Library. The text terms used were: Attention Deficit Hyperactivity Disorder and Hyperkinetic Disorder. These were used in combination with the subject headings: Parent Education, Social Skills Training, Cognitive Behavioral Therapy, School/ Academic Intervention, Pharmacological Intervention, and Multimodal Intervention. Synonyms and other key words that were combined using Boolean logic ("AND," "OR") were: ADHD, CBT, and Medication. Reference lists from key articles identified further studies for consideration. Hand searches of key journals in the subject, such as The Journal of Child Psychology and Psychiatry, The American Academy of Child and Adolescent Psychiatry, Archives of Disease in Childhood, Developmental Medicine and Child Neurology, and the British Journal of Psychiatry were also conducted. Book chapters and conference proceedings were also searched.

\section{Study selection}

Sources of evidence were refined and limited to:

1. English-only retrievable papers;

2. Longitudinal studies ( $\geq 1$ year);

3. Children/adolescents up to the age of 16 years; and

4. Where interventions involved parents, parents of children/adolescents, with children up to the age of 16 years.

Studies were eliminated if they:

1. Were not randomized controlled trials (RCTs);

2. Involved children/adolescents with no definitive diagnosis of ADHD/hyperkinetic disorder (DSM IV or ICD 10); or

3. Included interventions that were not recommended in the National Institute for Health and Care Excellence (NICE) guidelines. ${ }^{28}$

\section{Interventions}

Studies were included if they involved interventions that are recommended in the NICE guidelines. ${ }^{28}$ These are: parent education, social skills training, cognitive behavioral therapy, school/academic intervention, pharmacological intervention, and multimodal intervention(s). These were taken as currently recommended treatment strategies.

\section{Outcome}

This review focused on the methodological limitations of long-term randomized RCTs that have examined two key ADHD management issues; ADHD symptoms and academic achievement. The primary outcome for data extraction was
ADHD symptoms. The secondary outcome was academic achievement.

\section{Data extraction}

Titles and/or abstracts of studies retrieved using the search strategy and those from additional sources were screened independently by two review authors (JP/GW) to identify studies that potentially involved recommended interventions. The full text of these potentially eligible studies was retrieved and independently assessed for eligibility by two review authors (JP/GW). Any disagreements between them over the eligibility of particular studies were resolved through discussion with a third and fourth reviewer (NC/VH).

A standardized, pre-piloted form was used to extract data from the included studies, for assessment of study quality and evidence synthesis. Extracted information included: study setting; study population and participant demographics and baseline characteristics; details of the intervention and control conditions; study methodology; recruitment and study completion rates; outcomes and times of measurement; indicators of acceptability to users; suggested mechanisms of intervention action; information for assessment of the risk of bias. The four authors (JP/GW/NC/VH) extracted data independently; discrepancies were identified and resolved through discussion. Missing data was requested from study authors.

\section{Critical appraisal}

All twelve papers that fully met the eligibility criteria were evaluated against the Cochrane risk of bias tool ${ }^{37}$ by the four review authors independently. This tool consists of twelve questions against which the study validity, methodological quality results, and external validity of each paper was evaluated. Each paper was assessed following the appraisal criteria, with a score out of 12 being allocated to each (see Table 1).

A study with a low risk of bias was deemed as one fulfilling six or more of the criteria items and with no fatal flaw, such as:

1. Drop-out rate $>50 \%$; and

2. Statistically and clinically significant differences between groups at baseline, indicating unsuccessful randomization. ${ }^{38}$

\section{Results}

A total of 18,809 citations were identified. These were refined by combining Parent Education, Social Skills Training, Cognitive Behavioral Therapy, School/Academic 


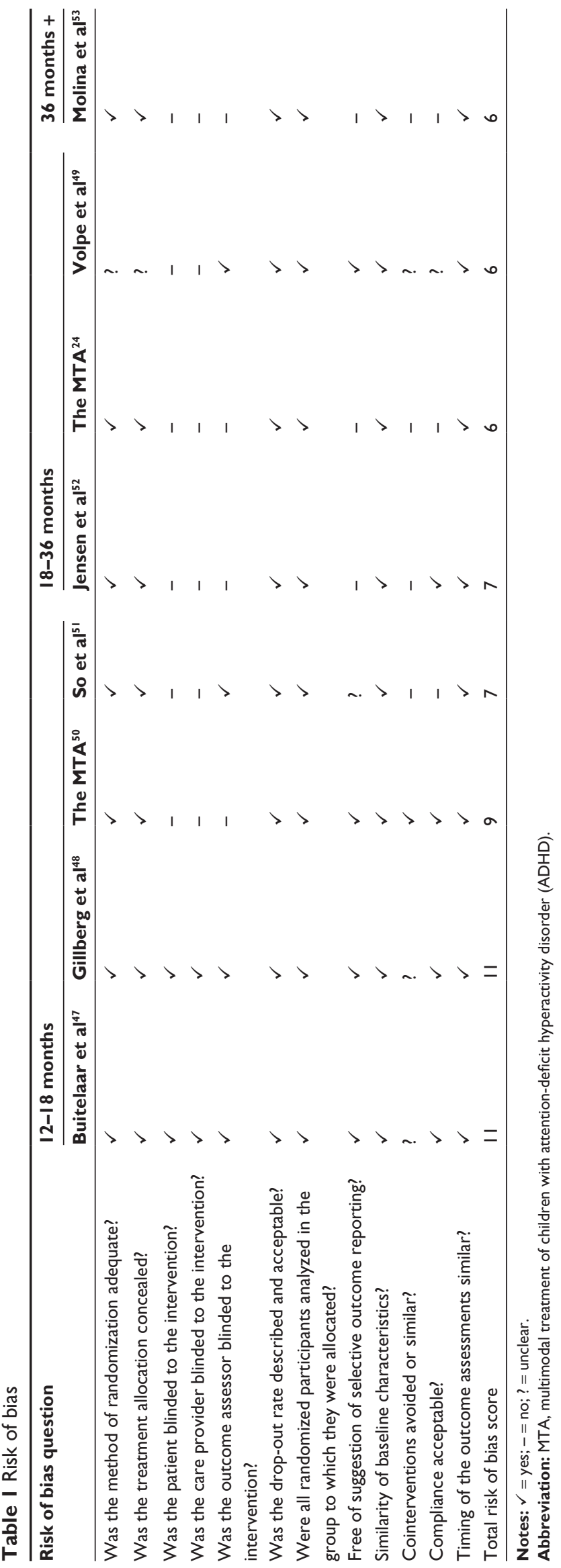

Intervention, Pharmacological Intervention, and Multimodal Intervention, with the key search terms (see above) eliminating 11,187 citations. A further 7,531 were eliminated, as they involved interventions that did not meet the inclusion/exclusion criteria (see above), leaving 90 papers. Abstracts of the remaining 90 papers were scrutinized, and full papers of all citations where the methodology was unclear were accessed. This led to a further 73 citations being eliminated, leaving 17 papers, of which a further five were eliminated as they did not include the primary and secondary outcomes. ${ }^{25,39-42}$ Those that achieved a score of less than 6 were also removed (four) but are described briefly below. Figure 1 depicts the study selection process.

The four trials that met the inclusion criteria for this review but which fell beneath the risk of bias cutoff score were Abikoff et al; ${ }^{43,44} \mathrm{Hechtman}$ et al $;{ }^{45}$ and Charach et al, ${ }^{46}$ scoring 5, 5, 5, and 3 respectively. With further description of the method of randomization and of whether treatment allocation was concealed, the studies by Abikoff et a ${ }^{43,44}$ and Hechtman et al, ${ }^{45}$ would have met the risk of bias cutoff score. Nevertheless, these studies compared methylphenidate; methylphenidate and psychosocial intervention; and methylphenidate and attention control psychosocial treatment arms, in 7- to 9-year-old participants over a 2 -year period $(n=103)$. They reported significant improvements in symptoms, social functioning, and academic achievement across all treatments and continued for 2 years. However, no advantage was found for any of the three treatment arms.

Charach et $\mathrm{al}^{46}$ evaluated the impact of adherence and medication status on the effectiveness and adverse effects of stimulant use in children (aged 6-12 at baseline) with ADHD over 5 years $(n=88)$. They found that at 2 years, adherents $(n=41)$ showed greater improvements in teacher-reported symptom scores than those off medication $(\mathrm{n}=16)$ and nonadherents on medication $(\mathrm{n}=16)(P<0.02)$. At 5 years, adherents $(\mathrm{n}=16)$ showed greater improvements in teacher reported symptom scores than nonadherents on medication $(\mathrm{n}=15)$ and those off medication $(\mathrm{n}=14)(P<0.04)$.

These findings are consistent with those trials using more robust methodological designs; however, because this trial fell well below the risk of bias cutoff score and because of the small sample size, the results should be interpreted with caution.

\section{Included papers}

Of the eight remaining papers, five were separate studies, with four of the eight involving one cohort (in the multimodal treatment of children with ADHD [MTA] study $)^{25,50,52,53}$ being 


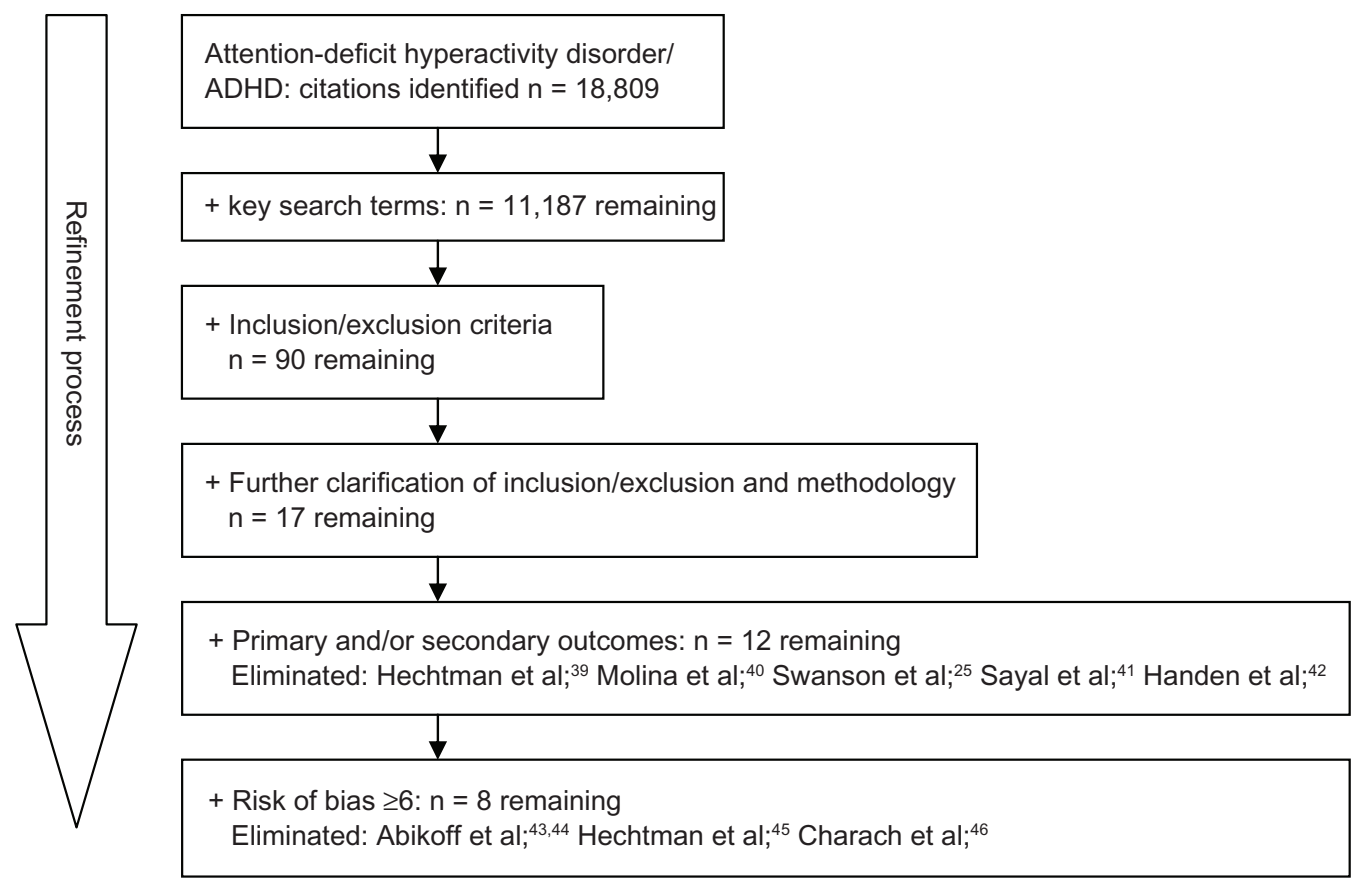

Figure I The study selection process.

Abbreviation: ADHD, attention-deficit hyperactivity disorder.

followed up at 14, 24, 36, and 96 months. The eight papers were divided into three timescales: studies with outcomes between 12 to 18 months (four); studies with outcomes between 18 to 24 months (one); studies with outcomes between 24 months to 36 months (two); and finally, studies with outcomes over 36 months (one). This allowed for the methodological rigor to be examined over time. It is important to note that after the initial 14-month period in the MTA trial, the cohorts were no longer distinct. The longer-term follow-up studies are included despite this and demonstrate the difficulties with long-term studies. Table 1 displays the completed risk of bias tool consensus scores, in time order (shortest to longest).

\section{Study characteristics}

Table 2 provides a summary of the included studies, along with the age, sample size, intervention, study duration, outcome measures used, and the main results. Two of the studies involved pharmaceutical treatment only, ${ }^{47,48}$ one involved an academic intervention only, ${ }^{49}$ and the remaining five included a combined pharmaceutical and behavioral management ("Comb") intervention, four of which were follow ups of the MTA study. ${ }^{24,50-53}$ The age of the participants ranged from 6 to 11 years at baseline, and studies that included a behavioral component involved participants aged $7-9^{50}$ and $7-9.9$ years. ${ }^{51}$ The total number of participants in the studies was 1,057 , of which $579(54.7 \%)$ were from the MTA. Furthermore, only one study other than the MTA measured outcomes beyond 18 months. ${ }^{49}$ Five of the studies involved American cohorts; the other three studies involved cohorts in Europe, Israel, South Africa, and Australia.

\section{Studies with outcomes measured up to 18 months Medication}

Two studies examined the use of medication only. ${ }^{47,48}$ Gillberg et $\mathrm{al}^{48}$ studied the effects of amphetamine on symptoms of ADHD over a 15-month active treatment period. Their double-blind multicentre (Sweden) RCT $(n=62)$ revealed that the treatment group obtained significantly lower Conners' Parent and Teacher Rating Scales outcomes than did the placebo group $(P=0.02)$. However, as a result of the difficulties in maintaining double-blind conditions for the 15 -months treatment period, only $27 \%$ of the original cohort assigned to placebo completed randomized treatment through to month 15.

Buitelaar et $\mathrm{al}^{47}$ carried out a double-blind multicentre (Europe - 24 centers, South Africa - four centers, Israel - two centers, Australia - three centers) RCT $(n=163)$ to investigate the efficacy of atomoxetine in maintaining symptom response (preventing relapse) following 1 year of treatment. Using the ADHD Rating Scale IV (ADHD RS) as the primary outcome measure (described in DuPaul et a ${ }^{54}$ ), they found that participants who initially responded during 

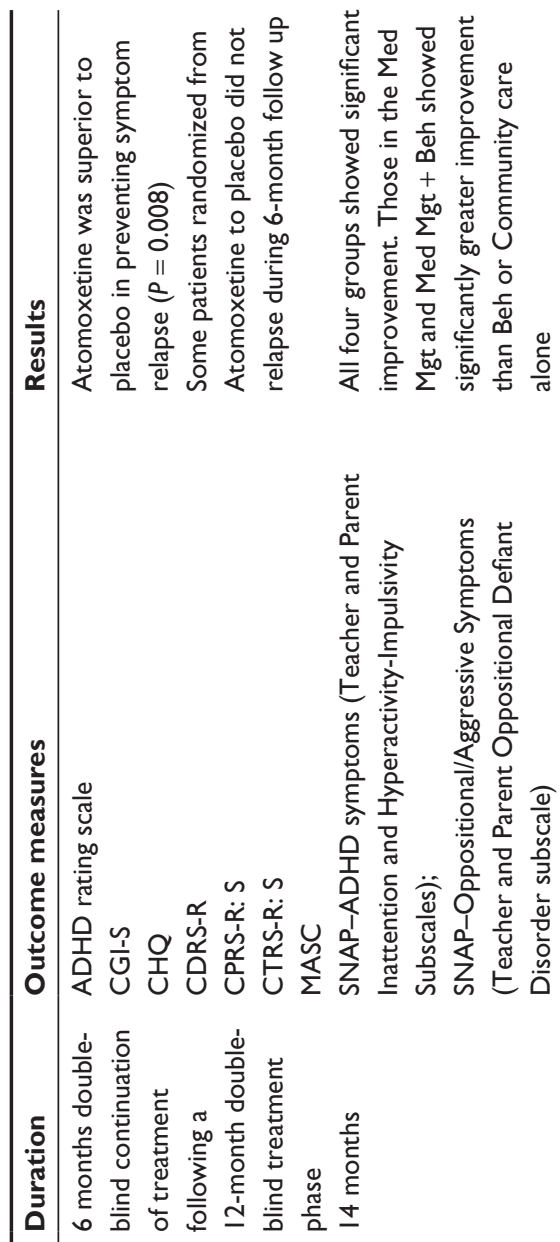
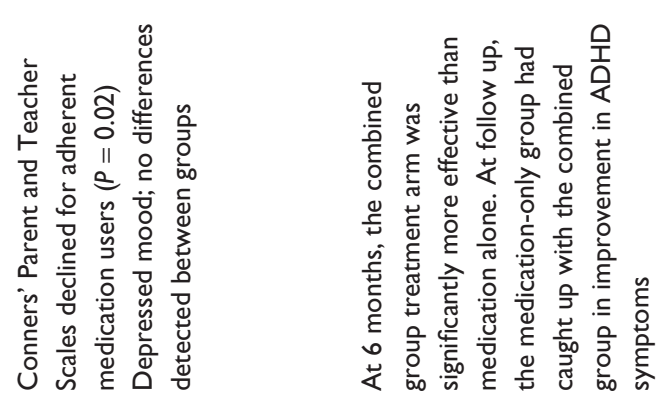

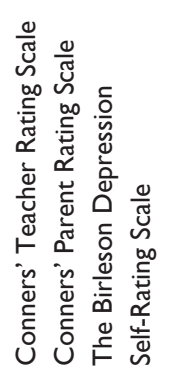

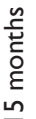
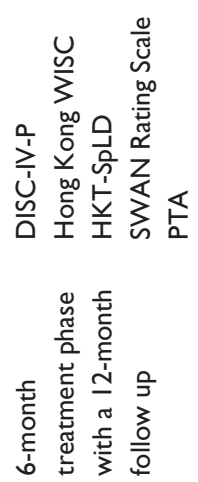

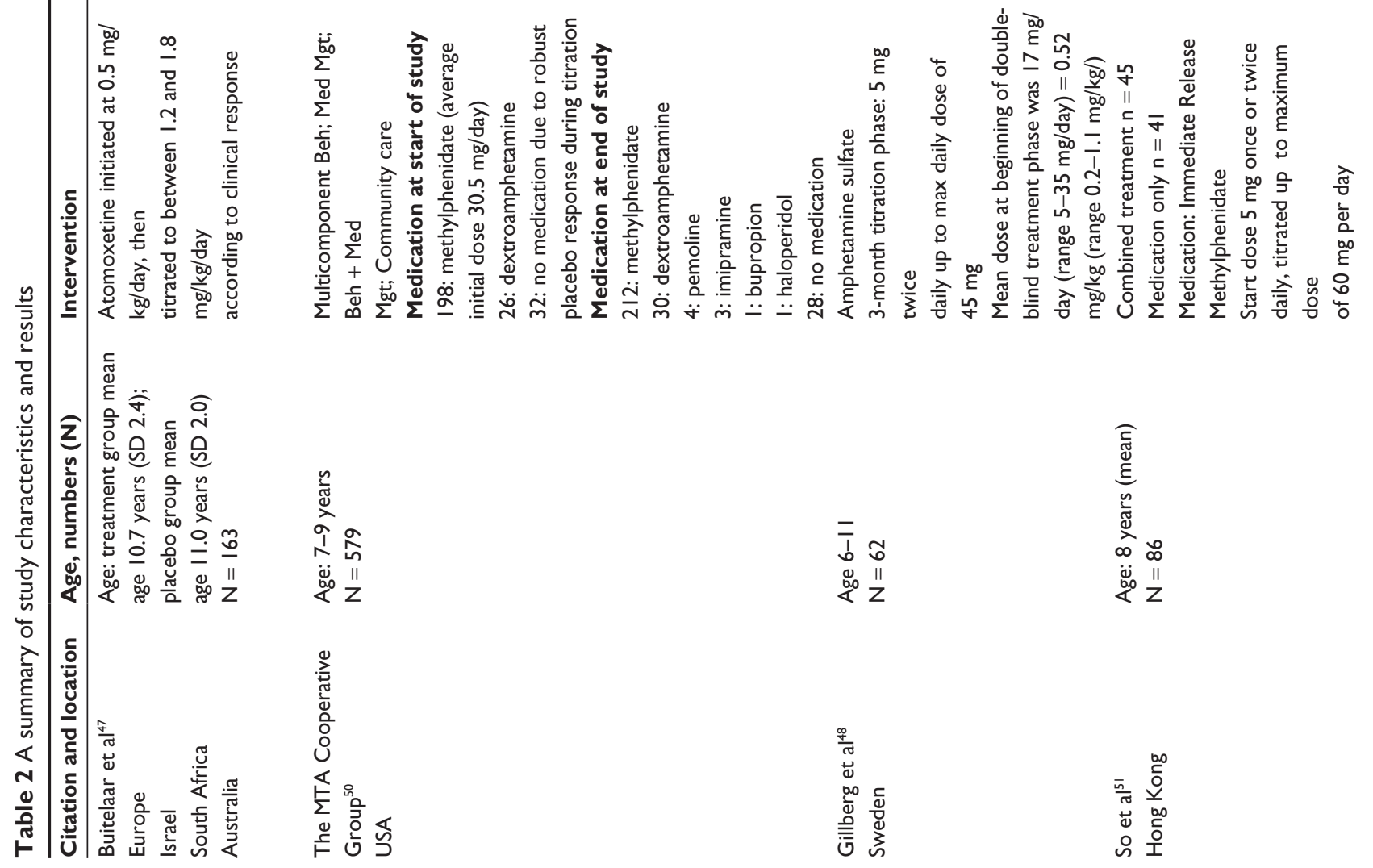



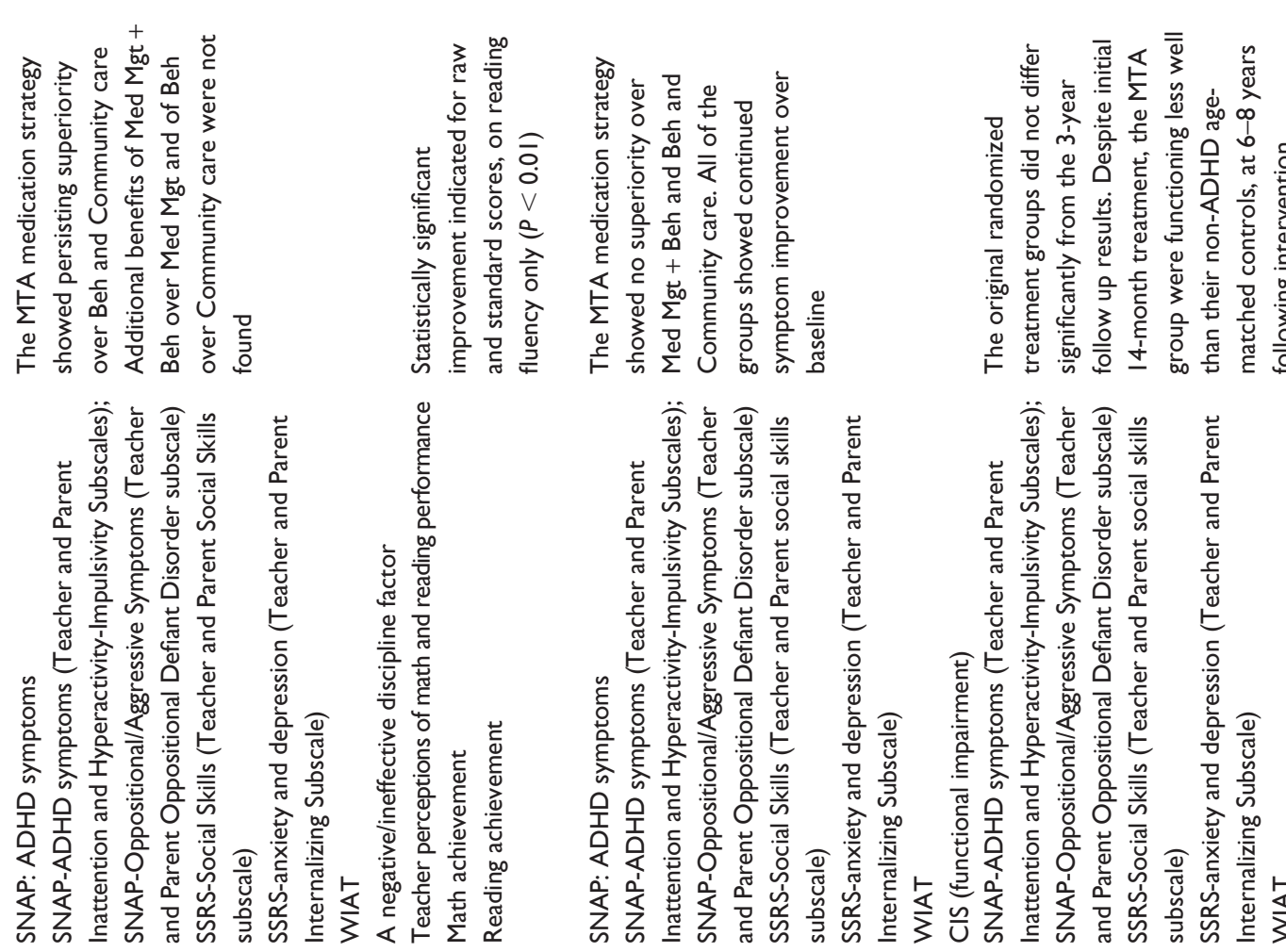

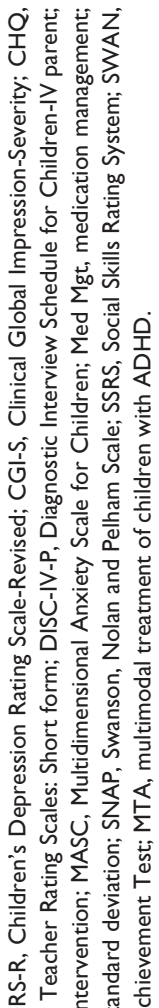

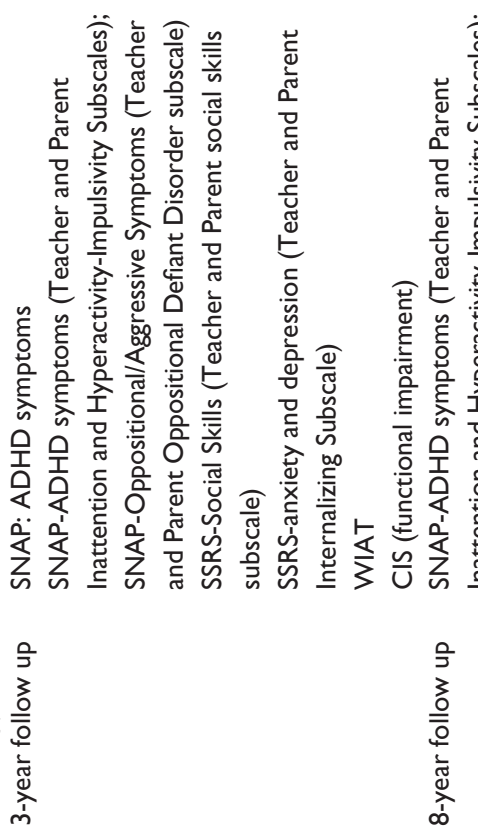

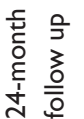

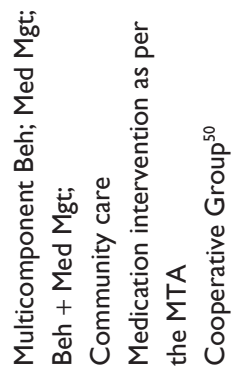
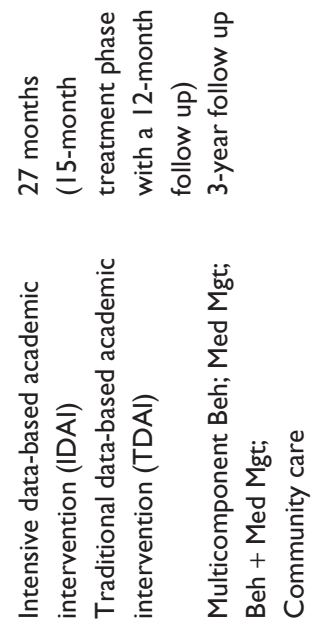

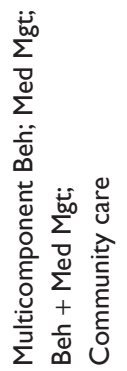

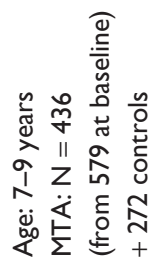

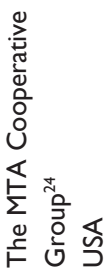

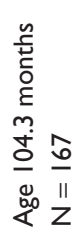

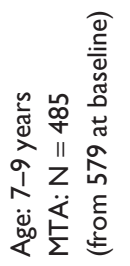

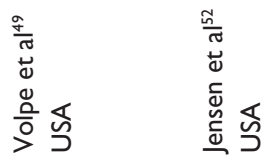

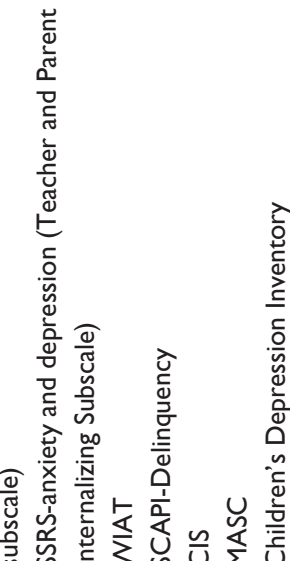

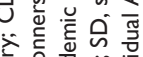

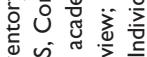

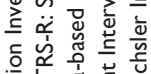

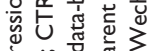

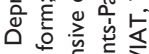

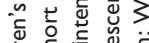

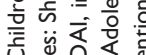

$\overline{0}$ 出 b. च

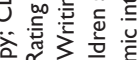

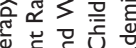

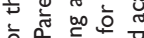

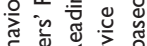

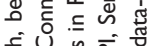

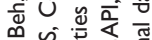

vi

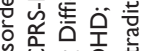

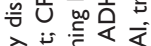

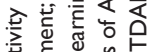

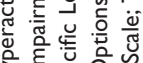

空

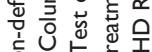

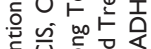

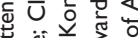

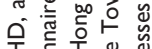

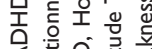

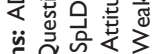

은 도 至 둥

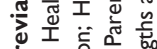

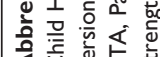


the acute phase (10 weeks) and continued treatment for 1 year were associated with outcomes that were superior to the control group at preventing relapse of symptom severity $(P=0.008)$ and symptom response $(P=0.001)$. Interestingly, they also found that a significant proportion of those randomized to switch from atomoxetine to placebo after a period of stable treatment for 1 year did not relapse during the 6-month follow up, suggesting that initial gains may be consolidated following a period of medication. However, natural selection bias, such as adverse effects, adherence/ protocol violations, as well as the length of time medicated and the gender ratio (9:1 male to female) may have limited the external validity of the results.

\section{Multimodal}

Two studies investigated the efficacy of Comb treatment over 14 months $^{50}$ and 18 months (6-month treatment phase with a 12-month follow up). ${ }^{51}$ The MTA compared the efficacy of medication (careful titration followed by monthly visits) only ("Med Mgt"); intensive behavioral treatment only ("Beh"); Comb treatment; and standard community care provided by community providers ("CC"). The MTA behavioral intervention included intensive parent-, child-, and school-based interventions, based on previous work. ${ }^{55-59}$ Parent training involved 27 group and eight individual sessions per family, which began weekly on randomization. The child-focused treatment was a summer treatment program (summer camp) over 8 weeks, 5 days per week, 9 hours per day. The schoolbased treatment involved 10-16 sessions of biweekly teacher consultation and 12 weeks (60 school days) of one-to-one aide provided by paraprofessionals who were involved in the summer camp. Families attended an average of $77.8 \%$ of parent training sessions and 36.2 of 40 possible summer camp days. The school component averaged 10.7 teacher consultation visits and 47.6 days (of 60 possible) of work with classroom aides.

Whilst all four groups showed significant improvement in all outcomes, those in the Med Mgt and Comb treatment groups showed significantly greater improvement (effect size $0.6)$ for ADHD symptoms than did the Beh treatment and CC groups (effect size 0.39) $(P \leq 0.02)$. Whilst the study found insignificant difference between the Comb and Med Mgt for ADHD symptoms, the Comb treatment did show superiority for a number of outcomes, including social skills (using the Social Skills Rating System [SSRS]), reading, mathematics, and spelling (using the Wechsler Individual Achievement Test [WIAT]). However, in light of the fact that two-thirds of the CC group in the MTA study were given medication but documented the least improvement, a Hong Kong-based study by So et al, ${ }^{51}$ specifically compared Med Mgt $(n=41)$ with Comb treatment $(n=45)$. This trial also involved an intensive behavioral intervention which consisted of 24 weekly group session lasting approximately 100 minutes over a 6-month period. This included classroom management, skills training, and separate parent training sessions. Adherence was maintained in over $80 \%$ of participants in both treatment arms.

They found that at 6 months, the Comb group treatment arm was significantly more effective than Med Mgt for treating ADHD symptoms. However, at follow up (18 months), the Med Mgt group had caught up with the Comb group in improvement in ADHD symptoms.

\section{Studies with outcomes measured between 18-36 months}

\section{Academic intervention}

Volpe et $\mathrm{al}^{49}$ evaluated the effectiveness of an intensive data-based academic intervention (IDAI) with traditional data-based academic intervention (TDAI) implemented over 15 months (see Du Paul et $\mathrm{al}^{60}$ and Jitendra et al, ${ }^{61}$ for the specific intervention design). The IDAI differed from the TDAI in that consultants collaborated with classroom teachers to design academic interventions based on assessment data, treatment integrity, and the provision of feedback on progress, as opposed to academic interventions based on teacher choice and no feedback. At 1-year follow up, they found that significant improvement was only indicated in two of the 16 outcomes (reading and math fluency $P<0.01$ ) for the IDAI group. However, in relation to the postintervention scores, students in both groups tended to maintain, although not necessarily improve upon, intervention gains. This highlights the need for sustained long-term intervention as these individuals progress through their education.

\section{Multimodal}

The MTA study group followed up their multimodal treatment study ${ }^{50}$ at 24 months ${ }^{24}$ and 36 months. ${ }^{52}$ In the primary analysis, the main effect of assigned treatments was significant for ADHD symptoms $(P<0.0001)$ but not for social skills $(P<0.06)$ or reading $(P<0.38)$. The Comb and Med Mgt groups showed persisting superiority over the Beh and $\mathrm{CC}$ groups. However, additional benefits of Comb treatment over Med Mgt and of Beh over CC were not found. In addition, as a result of crossover, heterogeneity of choice within each treatment group, and compliance, the attenuation of effect size reduced from 0.6 (at 14 months) to 0.3 for ADHD 
symptoms. The percentage of participants taking medication in the Beh and CC groups had also increased from 14\% and $60 \%$ (at 14 months) to $38 \%$ and $62 \%$, respectively.

At 3 years, in contrast to the findings at 24 months, 485 of the original 579 participants in the treatment groups did not differ significantly on any of the MTA outcome measures. The overall percentage of participants taking medication had increased by $50 \%$ over the 14 - to 36 -month time period, whereby the Beh group had increased from 14\%-45\%, the CC group remained constant, from $60 \%-62 \%$, and the Med Mgt group had significantly decreased from $91 \%$ to $71 \%$. The effect sizes for all of the treatment groups showed substantial improvement over baseline, with sizes of 1.6-1.7 for ADHD, $0.8-0.9$ for social skills, and $0.1-0.2$ for reading. Therefore, although the treatment groups that involved the medication algorithm showed initial superiority, this study suggests that at 36 months, all of the treatment interventions had positive outcomes. Importantly, after the initial strict groupings for 14 months, all participants were effectively receiving CC. However, the MTA also concluded that these findings may be a result of age-related decline in ADHD symptoms, changes in medication management and intensity, and compliance. In other words, by 36 months there was little difference between groups in terms of their treatment and symptoms.

\section{Studies with outcomes measured beyond \\ $36+$ months \\ Multimodal}

Only one paper ${ }^{53}$ examining outcomes beyond 36 months met the review criteria. The MTA followed up the 14-, 24-, and 36-month outcomes with a prospective follow up of children treated within the original cohort $(s)^{50}$ at $6-8$ years $(n=436)$. They also examined the functioning level of the original MTA participants in comparison with a local normative comparison group $(\mathrm{n}=261)$. Their mixed-effects regression models revealed that the original randomized treatment groups did not differ from the 3-year results; ${ }^{52}$ the ADHD symptom trajectory in the first 3 years predicted $55 \%$ of the outcomes; and the use of medication had decreased $62 \%$ after the initial 14-month randomization period. However, they concluded that despite initial 14-month treatment, the MTA group was still functioning less well than their non-ADHD age-matched controls, 6-8 years following the intervention.

\section{Discussion}

This review has highlighted the paucity of evidence and the limitations of examining the long-term outcomes of recommended interventions for managing ADHD symptoms.
Only eight papers met the criteria for this review, four of which involved the same cohort.

Existing studies examining the effectiveness of interventions suggest that relatively short-term interventions $(<1$ year), including Comb treatment (medication and Beh interventions), and Med Mgt are effective in treating ADHD symptoms, despite the level of severity. The findings of this review suggest that the effectiveness of recommended interventions may extend beyond 1 year and possibly up to 8 years albeit with reducing effect size, but the lack of continuing randomization makes these longer-term findings difficult to interpret. Additionally, as ADHD persists, those with the disorder will reach a similar level of functioning despite the initial level of severity or treatment provided, which will still be significantly below those without ADHD. For academic performance, those who receive Comb treatment ${ }^{24,50-53}$ may improve academic performance, and the provision of a personalized, intensive classroom intervention may improve reading fluency. ${ }^{51}$

However, this review has highlighted the limitations in applying existing evidence to the long-term impact ADHD can have on those affected.

\section{Limitations of existing evidence}

The definition of "long-term" and "treatment as usual" remains heterogeneous between studies. As there is no definitive explanation of these terms, difficulties remain in the evaluation of findings over time and of what exactly "treatment as usual" consists. We chose to include studies with greater than 1-year follow up. In general, studies examining the effects of treatments, both pharmacological and nonpharmacological, last up to 12 weeks. Other recent reviews looking at longer-term outcomes have included studies of over 2 years ${ }^{35}$ or 3 years. ${ }^{36}$ Evidence indicates that ADHD is a chronic disorder that spans from childhood through to adulthood. Therefore, the definition of longterm, when applied to relatively short periods of time (ie, 1 year), may be inappropriate within the context of ADHD, where "treatment as usual" may differ for younger to older service users. Secondly, it is well understood that each case of ADHD is unique in physical and functional impairments, possible comorbidities, and personal and environmental contextual factors. ${ }^{11}$ In addition, each clinic may have varying models of service delivery and multidisciplinary teams. Therefore, evaluating the effectiveness of interventions against control arms where cases and clinics are not fully described becomes problematic. Thirdly, the studies included in this review have involved a number of countries 
(Table 2) and cultural backgrounds, such as, Caucasian, African American, Hispanic, ${ }^{50}$ Chinese (Hong Kong), European, Israeli, South African, ${ }^{47}$ and Swedish. ${ }^{48}$ However, it should be noted that the vast majority of participants in these studies were western (US) Caucasian, and there is a distinct lack of evidence that includes UK, European, and Asian populations.

Whilst the trials in this review had adequate adherence to treatment rates and met the criteria for risk of bias dropout rates, it should be noted that some participants were switched to alternative medication as a result of efficacy or tolerability. For example, by the MTA study end, 212 (73.4\%) of the 289 subjects given Med Mgt and Comb treatment were being successfully maintained on short acting methylphenidate, 30 (10.4\%) on dextroamphetamine, four $(1.4 \%)$ on pemoline, three $(1.0 \%)$ on imipramine, one $(0.3 \%)$ on bupropion, one $(0.3 \%)$ on haloperidol, and $18(3.1 \%)$ on no medication. Therefore, the results cannot be attributable to one form of medication alone, and as a result of clinical (ie, adverse side effects) and personal decisions (ie, a desire to withdraw), some participants were unable to adhere to long-term treatment arms. ${ }^{62}$ Following their review of adverse events in studies lasting from 1 to 32 weeks, Aagaard and Hansen ${ }^{63}$ concluded that there was a lack of good evidence about adverse effects during longterm medication use.

This review has exposed the plethora of outcome measures used between studies. The papers included in this review have used no fewer than 26 different outcome measures to examine the effectiveness of interventions. Whilst this in itself may underline the complexity of the disorder and the differences surrounding each case, there is very little explanation of comorbidity, cultural, and contextual issues beyond demographics that are known to impact on ADHD symptoms. ${ }^{64}$ The limitation in methodological adherence is highlighted in Table 1, whereby longer studies have a lower risk of bias score compared with shorter studies. However, it is clearly difficult to ethically avoid cointerventions over time, when further treatment is indicated. Whilst the MTA has become the mainstay of ADHD intervention effectiveness evaluation, this also became a naturalistic study after 14 months, ${ }^{50}$ and although attempts were made to separate treatment modalities, unimodal therapy singular efficacy continues to be underresearched. Therefore the longer-term effect of recommended singular interventions remains questionable.

ADHD symptoms and its associated functional impairment(s) may change as a result of maturation as well as of changes in contextual conditions. ${ }^{10}$ There are a number of studies that have explored the functional long-term outcomes of ADHD through childhood, adolescence, and into adulthood. These studies all indicate that long-term symptoms and functional impairment persist well into older years. ${ }^{20,65-67}$ Indeed, functional impairment differs from childhood through to adulthood; for example, in school age children, hyperactivity, academic performance, and low self-esteem may be the focus of impairment. ${ }^{10}$ In adults, the impairments surrounding substance abuse, social skills, and maintaining an occupation are associated with ongoing ADHD. ${ }^{10}$ Therefore, the monitoring of impairment and symptom control throughout the life course of ADHD is paramount.

Despite ongoing clinical need and adult prevalence, as children move through adolescence and into adulthood, their adherence to treatment diminishes. ${ }^{35}$ Therefore careful monitoring of adherence to treatment, symptom change, and impairment(s) throughout continued impairment is essential. However, there are few longitudinal studies that explore the effectiveness of interventions into adulthood and the link between intervention(s) provided, symptom severity, and functional impairment.

Research is required to explore the effectiveness of recommended interventions over the life course of ADHD, in other words, if intervention " $\mathrm{x}$ " is provided in childhood, how does this impact on adult impairment(s)? With advances in data management and technological applications for healthcare, ${ }^{68}$ innovative models of service delivery and evaluation may overcome a number of the limitations associated with long-term research designs and monitoring of ADHD. ${ }^{69}$

This review has not examined the role of comorbidities in long-term outcomes, although some data does exist. Within clinical practice, the majority of children/adolescents and adults have one or more comorbidities. ${ }^{1-3}$ Cherkasova et al ${ }^{70}$ recently reviewed the developmental course of ADHD and its predictors, demonstrating the negative impact of comorbidities. However, more research is needed in this area to reflect "real life" situations.

Finally, we chose to only include interventions recommended by the NICE Guideline Group, using stringent evidence base. Gillies et al, ${ }^{71}$ reviewed the use of polyunsaturated fatty acids in the treatment of ADHD and found no definite evidence of efficacy, and Lofthouse et al, ${ }^{72}$ similarly failed to demonstrate conclusive benefit from neurofeedback. Further research may be helpful in examining the role of alternative therapies. 


\section{Conclusion}

This review has highlighted the paucity of evidence and the limitations of examining the long-term outcomes of recommended interventions for managing ADHD symptoms. As a result of difficulty maintaining robust study design, the complexity of the disorder, and natural life course changes, there is little evidence to suggest that the effects observed over the relatively short-term are maintained throughout longer periods of impairment. Furthermore, much of the existing evidence examining effectiveness beyond 12 months does not include newer medications currently available, nor examine contextual and cultural differences, such as UK/European and Asian populations. Longitudinal studies examining the longterm outcomes of treating ADHD with currently recommended service interventions are needed, to plan and improve service delivery and patient outcomes. Long-term studies should include the whole spectrum of ADHD and coexisting disorders.

\section{Acknowledgments}

The research for this manuscript was funded by Sheffield Children's Hospital Charity but is published with the support of The National Institute for Health Research Collaboration for Leadership in Applied Health Research and Care for South Yorkshire (NIHR CLAHRC SY). The views and opinions expressed are those of the authors and not necessarily those of the NHS, the NIHR or the Department of Health. CLAHRC SY would also like to acknowledge the participation and resources of our partner organizations. Further details can be found at www.clahrc-sy.nihr.ac.uk.

\section{Disclosure}

The authors report no conflicts of interest in this work.

\section{References}

1. Biederman J, Newcom J, Sprich S. Comorbidity of attention deficit hyperactivity disorder with conduct, depressive, anxiety and other disorders. Am J Psychiatry. 1991;148(5):564-577.

2. Kadesjö B, Gillberg C. The comorbidity of ADHD in the general population of Swedish school-age children. J Child Psychol Psychiatry. 2001;42(4):487-492.

3. Yoshimasu K, Barbaresi WJ, Colligan RC, et al. Childhood ADHD is strongly associated with a broad range of psychiatric disorders during adolescence: a population-based birth cohort study. J Child Psychol Psychiatry. 2012;53(10):1036-1043.

4. Polanczyk G, de Lima MS, Horta BL, Biederman J, Rohde LA. The worldwide prevalence of ADHD: a systematic review and metaregression analysis. Am J Psychiatry. 2007;164(6):942-948.

5. Weiss G, Hechtman L, Milroy T, Perlman T. Psychiatric status of hyperactives as adults: a controlled prospective 15-year follow-up of 63 hyperactive children. J Am Acad Child Psychiatry. 1985;24(2):211-220.

6. Barkley RA, Fischer M, Edelbrock CS, Smallish L. The adolescent outcome of hyperactive children diagnosed by research criteria: I. An 8-year prospective follow-up study. J Am Acad Child Adolesc Psychiatry. 1990;29(4):546-557.
7. Biederman J, Faraone S, Milberger S, et al. Predictors of persistence and remission of ADHD into adolescence: results from a four-year prospective follow-up study. J Am Acad Child Adolesc Psychiatry. 1996;35(3):343-351.

8. Gittelman R, Mannuzza S, Shenker R, Bonagura N. Hyperactive boys almost grown up. I. Psychiatric status. Arch Gen Psychiatry. 1985;42(10):937-947.

9. Faraone SV, Biederman J, Mick E. The age-dependent decline of attention deficit hyperactivity disorder: a meta-analysis of follow-up studies. Psychol Med. 2006;36(2):159-165.

10. Harpin VA. The effect of ADHD on the life of an individual, their family, and community from preschool to adult life. Arch Dis Child. 2005;90 Suppl 1:i2-i7.

11. Biederman J, Faraone SV. Attention-deficit hyperactivity disorder. Lancet. 2005;366(9481):237-248.

12. Pliszka SR. Comorbidity of attention-deficit/hyperactivity disorder with psychiatry disorder: an overview. J Clin Psychiatry. 1998;59 Suppl 7: 50-58.

13. Loe IM, Feldman HM. Academic and educational outcomes of children with ADHD. J Pediatr Psychol. 2007;32(6):643-654.

14. Frazier TW, Youngstrom EA, Glutting JJ, Watkins MW. ADHD and achievement: meta-analysis of the child, adolescent, and adult literatures and a concomitant study with college students. J Learn Disabil. 2007;40(1):49-65.

15. McGee R, Partridge F, Williams S, Silva PA. A twelve-year follow-up of preschool hyperactive children. JAm Acad Child Adolesc Psychiatry. 1991;30(2):224-232.

16. Biederman J, Monuteaux MC, Mick E, et al. Young adult outcome of attention deficit hyperactivity disorder: a controlled 10-year follow-up study. Psychol Med. 2006;36(2):167-179.

17. Bussing R, Mason DM, Bell L, Porter P, Garvan C. Adolescent outcomes of childhood attention-deficit/hyperactivity disorder in a diverse community sample. J Am Acad Child Adolesc Psychiatry. 2010;49(6): 595-605.

18. Mannuzza S, Klein RG, Bessler A, Malloy P, LaPadula M. Adult psychiatric status of hyperactive boys grown up. Am J Psychiatry. 1998;155(4):493-498.

19. Taylor E, Chadwick O, Heptinstall E, Danckaerts M. Hyperactivity and conduct problems as risk factors for adolescent development. J Am Acad Child Adolesc Psychiatry. 1996;35(9):1213-1226.

20. Klein RG, Mannuzza S, Olazagasti MA, et al. Clinical and functional outcome of childhood attention-deficit/hyperactivity disorder 33 years later. Arch Gen Psychiatry. 2012;69(12):1295-1303.

21. McCarthy S, Wilton L, Murray ML, Hodgkins P, Asherson P, Wong IC. The epidemiology of pharmacologically treated attention deficit hyperactivity disorder (ADHD) in children, adolescents and adults in UK primary care. BMC Pediatr. 2012;12:78.

22. National Institute for Health and Clinical Excellence. Methylphenidate, Atomoxetine and Dexamfetamine for the Treatment of Attention Deficit Hyperactivity Disorder in Children and Adolescents [Review of Technology Appraisal 98]. London: NICE; 2006. Available from: http:/guidance. nice.org.uk/TA98/Guidance/pdf/English. Accessed July 2, 2013.

23. Cherland E, Fitzpatrick R. Psychotic side effects of psychostimulants: a 5-year review. Can J Psychiatry. 1999;44(8):811-813.

24. MTA Cooperative Group. National Institute of Mental Health Multimodal Treatment Study of ADHD follow-up: 24-month outcomes of treatment strategies for attention-deficit/hyperactivity disorder. Pediatrics. 2004;113(4):754-761.

25. Swanson JM, Elliott GR, Greenhill LL, et al. Effects of stimulant medication on growth rates across 3 years in the MTA follow-up. JAm Acad Child Adolesc Psychiatry. 2007;46(8):1015-1027.

26. Cascade E, Kalali AH, Wigal SB. Real-world data on: attention deficit hyperactivity disorder medication side effects. Psychiatry (Edgmont). 2010;7(4):13-15.

27. Toomey SL, Sox CM, Rusinak D, Finkelstein JA. Why do children with ADHD discontinue their medication? Clin Pediatr (Phila). 2012;51(8):763-769. 
28. National Collaborating Centre for Mental Health. Attention Deficit Hyperactivity Disorder: Diagnosis and Management of ADHD in Children, Young People and Adults [National Clinical Guidelines, Number 72]. Leicester: The British Psychological Society; 2009.

29. Storebø OJ, Skoog M, Damm D, Thomsen PH, Simonsen E, Gluud C. Social skills training for Attention Deficit Hyperactivity Disorder (ADHD) in children aged 5 to 18 years. Cochrane Database Syst Rev. 2011:CD008223.

30. Zwi M, Jones H, Thorgaard C, York A, Dennis JA. Parent training interventions for Attention Deficit Hyperactivity Disorder (ADHD) in children aged 5 to 18 years. Cochrane Database Syst Rev. 2011:CD003018.

31. Langley K, Fowler T, Ford T, et al. Adolescent clinical outcomes for young people with attention-deficit hyperactivity disorder. $\mathrm{Br} J$ Psychiatry. 2010;196(3):235-240.

32. McCarthy S, Asherson P, Coghill D, et al. Attention-deficit hyperactivity disorder: treatment discontinuation in adolescents and young adults. Br J Psychiatry. 2009;194(3):273-277.

33. Woodward L, Dowdney L, Taylor E. Child and family factors influencing the clinical referral of children with hyperactivity: a research note. $J$ Child Psychol Psychiatry. 1997;38(4):479-485.

34. Ford T, Fowler T, Langley K, Whittinger N, Thapar A. Five years on: public sector service use related to mental health in young people with ADHD or Hyperkinetic Disorder five years after diagnosis. Child Adolesc Ment Health. 2008;13(3):122-129.

35. Shaw M, Hodgkins P, Caci H, et al. A systematic review and analysis of long-term outcomes in attention deficit hyperactivity disorder: effects of treatment and non-treatment. BMC Med. 2012;10:99.

36. Langberg JM, Becker SP. Does long-term medication use improve the academic outcomes of youth with attention-deficit/hyperactivity disorder? Clin Child Fam Psychol Rev. 2012;15(3):215-233.

37. Furlan AD, Pennick V, Bombardier C, van Tulder M; Editorial Board, Cochrane Back Review Group. 2009 updated method guidelines for systematic reviews in the Cochrane Back Review Group. Spine. 2009;34(18):1929-1941.

38. van Tulder MW, Suttorp M, Morton S, Bouter LM, Shekelle P. Empirical evidence of an association between internal validity and effect size in randomized controlled trials of low-back pain. Spine. 2009;34(16):1685-1692.

39. Hechtman L, Abikoff H, Klein RG, et al. Children with ADHD treated with long-term methylphenidate and multimodal psychosocial treatment: impact on parental practices. JAm Acad Child Adolesc Psychiatry. 2004;43(7):830-838.

40. Molina BS, Flory K, Hinshaw SP, et al. Delinquent behavior and emerging substance use in the MTA at 36 months: prevalence, course, and treatment effects. J Am Acad Child Adolesc Psychiatry. 2007;46(8):1028-1040.

41. Sayal K, Owen V, White K, Merrell C, Tymms P, Taylor E. Impact of early school-based screening and intervention programs for ADHD on children's outcomes and access to services: follow-up of a school-based trial at age 10 years. Arch Pediatr Adolesc Med. 2010;164(5):462-469.

42. Handen BL, Janosky J, McAuliffe S. Long-term follow-up of children with mental retardation/borderline intellectual functioning and ADHD. J Abnorm Child Psychol. 1997;25(4):287-295.

43. Abikoff H, Hechtman L, Klein RG, et al. Symptomatic improvement in children with ADHD treated with long-term methylphenidate and multimodal psychosocial treatment. $J$ Am Acad Child Adolesc Psychiatry. 2004;43(7):802-811.

44. Abikoff H, Hechtman L, Klein RG, et al. Social functioning in children with ADHD treated with long-term methylphenidate and multimodal psychosocial treatment. J Am Acad Child Adolesc Psychiatry. 2004;43(7):820-829.

45. Hechtman L, Abikoff H, Klein RG, et al. Academic achievement and emotional status of children with ADHD treated with long-term methylphenidate and multimodal psychosocial treatment. J Am Acad Child Adolesc Psychiatry. 2004;43(7):812-819.

46. Charach A, Ickowicz A, Schachar R. Stimulant treatment over five years: adherence, effectiveness, and adverse effects. JAm Acad Child Adolesc Psychiatry. 2004;43(5):559-567.
47. Buitelaar JK, Michelson D, Danckaerts M, et al. A randomized, doubleblind study of continuation treatment for attention-deficit/hyperactivity disorder after 1 year. Biol Psychiatry. 2007;61(5):694-699.

48. Gillberg C, Melander H, von Knorring AL, et al. Long-term stimulant treatment of children with attention-deficit hyperactivity disorder symptoms: A randomized, double-blind, placebo-controlled trial. Arch Gen Psychiatry. 1997;54(9):857-864

49. Volpe RJ, DuPaul GJ, Jitendra AK, Tresco KE. Consultation-based academic interventions for children with attention deficit hyperactivity disorder: effects on reading and mathematics outcomes at 1-year follow-up. School Psych Rev. 2009;38(1):5-13.

50. A 14-month randomized clinical trial of treatment strategies for attention-deficit/hyperactivity disorder. The MTA Cooperative Group. Multimodal Treatment Study of Children with ADHD. Arch Gen Psychiatry. 1999;56(12):1073-1086.

51. So CY, Leung PW, Hung SF. Treatment effectiveness of combined medication/behavioural treatment with Chinese ADHD children in routine practice. Behav Res Ther. 2008;46(9):983-992.

52. Jensen PS, Arnold LE, Swanson JM, et al. 3-year follow-up of the NIMH MTA study. J Am Acad Child Adolesc Psychiatry. 2007;46(8): 989-1002.

53. Molina BSG, Hinshaw SP, Swanson JM, et al. The MTA at 8 years: prospective follow-up of children treated for combined-type ADHD in a multisite study. $J$ Am Acad Child Adolesc Psychiatry. 2009;48(5):484-500.

54. DuPaul GJ, Power TJ, Anastopoulos AD, Reid R. ADHD Rating ScaleIV: Checklists, Norms, and Clinical Interpretations. New York: The Guilford Press. 1998.

55. Barkley RA. Defiant Children: A Clinician's Manual for Assessment and Parent Training. New York, NY: Guilford Press; 1987.

56. Forehand RL, MacMahon RJ. Helping the Noncompliant Child: A Clinician's Guide to Parent Training. New York, NY: Guilford Press; 1980.

57. Pelham WE, Hoza B. Comprehensive treatment for ADHD: intensive summer treatment programs and follow-up. In Hibbs ED, Jensen PS, editors. Psychosocial treatments for child and adolescent disorders. Washington (DC): American Psychological Association. 1996; $311-40$.

58. Pelham WE, Wheeler T, Chronis A. Empirically supported psychosocial treatments for attention deficit hyperactivity disorder. J Clin Child Psychol. 1998;27(2):190-205.

59. Pelham WE Jr, Waschbusch DA. Behavioral intervention in AttentionDeficit Hyperactivity Disorder. In: Quay HC, Hogan AE, editors. Handbook of Disruptive Behavior Disorders. New York, NY: Plenum Publishing Corp; 1999:255-278.

60. DuPaul GJ, Jitendra AK, Volpe RJ, et al. Consultation-based academic interventions for children with ADHD: effects on reading and mathematics achievement. J Abnorm Child Psychol. 2006;34(5):635-648.

61. Jitendra AK, DuPaul GJ, Volpe RJ, et al. Consultation-based academic intervention for children with attention deficit hyperactivity disorder: School functioning outcomes. School Psych Rev. 2007;36(2): 217-236.

62. MTA Cooperative Group. National Institute of Mental Health Multimodal Treatment Study of ADHD follow-up: changes in effectiveness and growth after the end of treatment. Pediatrics. 2004;113(4): 762-769.

63. Aagaard L, Hansen EH. The occurrence of adverse drug reactions reported for attention deficit hyperactivity disorder (ADHD) medications in the pediatric population: a qualitative review of empirical studies. Neuropsychiatr Dis Treat. 2011;7:729-744.

64. Green H, McGinnity A, Meltzer H, Ford T, Goodman R. Mental Health of Children and Young People in Britain, 2004. Basingstoke: Palgrave MacMillan; 2005.

65. Barkley RA, Fischer M, Smallish L, Fletcher K. The persistence of attention-deficit/hyperactivity disorder into young adulthood as a function of reporting source and definition of disorder. J Abnorm Psychol. 2002;111(2):279-289. 
66. Barkley RA, Fischer M, Smallish L, Fletcher K. Young adult followup of hyperactive children: antisocial activities and drug use. J Child Psychol Psychiatry. 2004;45(2):195-211.

67. Mannuzza S, Klein RG, Bessler A, Malloy P, LaPadula M. Adult outcome of hyperactive boys. Educational achievement, occupational rank, and psychiatric status. Arch Gen Psychiatry. 1993;50(7):565-576.

68. NESTA. NESTA: Making Innovation Flourish. Annual Report and Accounts 2009. London: The Stationery Office; 2009.

69. Gringras P, Santosh P, Baird G. Development of an Internet-based realtime system for monitoring pharmacological interventions in children with neurodevelopmental and neuropsychiatric disorders. Child: Care, Health and Dev. 2006;32(5):591-600.
70. Cherkasova M, Sulla EM, Dalena KL, Pondé MP, Hechtman L. Developmental course of attention deficit hyperactivity disorder and its predictors. J Can Acad Child Adolesc Psychiatry. 2013;22(1): 47-54.

71. Gillies D, Sinn JKh, Lad SS, Leach MJ, Ross MJ. Polyunsaturated fatty acids (PUFA) for attention deficit hyperactivity disorder (ADHD) in children and adolescents. Cochrane Database Syst Rev. 2012;7:CD007986.

72. Lofthouse N, Arnold LE, Hersch S, Hurt E, DeBeus R. A review of neurofeedback treatment for pediatric ADHD. J Atten Disord. 2012;16(5):351-372.

\section{Publish your work in this journal}

Psychology Research and Behavior Management is an international, peerreviewed, open access journal focusing on the science of psychology and its application in behavior management to develop improved outcomes in the clinical, educational, sports and business arenas. Specific topics covered include: Neuroscience, memory \& decision making; Behavior modification \& management; Clinical applications; Business \& sports performance management; Social and developmental studies; Animal studies. The manuscript management system is completely online and includes a quick and fair peer-review system. Visit http://www.dovepress. com/testimonials.php to read real quotes from published authors.

Submit your manuscript here: http://www.dovepress.com/psychology-research-and-behavior-management-journal 